Stoa

Vol. 1, No. 1, 2010, pp. 21-35.

ISSN en trámite.

\title{
INVITACIÓN A LA OSCURIDAD Y A LO SUBTERRÁNEO
}

\author{
DANIEL H. CABRERA \\ Periodismo \\ Facultad de Filosofía y Letras \\ Universidad de Zaragoza \\ danhcab@unizar.es
}

\begin{abstract}
Semánticamente hablando, puede decirse que no hay luz sin tinieblas, mientras que lo inverso no es verdadero: porque la noche tiene una existencia simbólica autónoma.
\end{abstract}

G. Durand.

RESUMEN: El presente ensayo constituye una reconsideración de las significaciones sociales desde la importancia de los significados abandonados y olvidados. Se sugiere la posibilidad de apostar a dos metáforas - oscuridad y subterráneo- como forma de repensar la metafórica lumínica con la que se habla del pensamiento desde antiguo.

PALABRAS CLAVE: Significado, metáfora, imaginario.

SUMMARY: This essay is a review of social significances from the importance of the abandoned and forgotten meanings. It suggests the possibility of betting on two metaphors -darkness and undergroun- as a way of rethinking the metaphorical lighting with which he speaks of thought since ancient times.

KEY WORDS: Meaning, metaphor, imaginary.

\section{El que piensa ... pierde}

A la semejanza de los omnipresentes concursos que simulan la participación de "la gente", la sociedad de la conformidad generalizada se parece a una gran producción televisiva cuya consigna -anunciada a los gritos y con una amplia sonrisa-es: "el que piensa, pierde". La temporalidad que se impone 
en la sociedad contemporánea es la de la reacción instantánea, instintiva, breve. El teléfono celular es uno de sus máximos símbolos. Con él las respuestas se trasforman en un acto reflejo instantáneo siguiendo lo que parece ser su imperativo práctico "muévete por dónde quieras porque estarás siempre localizable”. El teléfono móvil es la combinación perfecta entre libertad corporal de movimiento y conexión social continua. Lo ilimitado que para Aristóteles era el terreno de los dioses o de las bestias - pero no de los humanos-aparece como el horizonte de la sociedad simbolizado por la tecnología. La otra cara de esta situación de estupidez se da en la educación en la que junto a la prioridad por el buen comportamiento dentro del aula se muestra que adaptarse es el camino más corto al éxito. En ella la enseñanza de la filosofía puede ser analizada a través de los ejemplos más comunes usados en los manuales. Estos avergüenzan y desalientan a quién pretenda adentrarse por el camino de la filosofía: "Sócrates es un hombre", " $2+2$ = 5", etc. La sencillez y estupidez de los ejemplos muestra una pereza tremenda por hacerse con la complejidad de lo social y lo humano. Pero esta situación no es casualidad sino consecuencia del imperativo de abstracción racional y de la necesidad moderna del método. Rara vez los ejemplos reflejan inquietudes cotidianas y existenciales. En cuanto a la ontología y la metafísica los modelos que se piensan están tomados de los seres de la naturaleza, muy rara vez se toma como modelo de ser los seres creados por el hombre: la rueda, una sinfonía, una obra literaria, una técnica, etc. Todo ello se presenta como un producto o imitación, nunca como auténtica creación. La cultura y la sociedad aparecen como ser segundo, nunca modelo de ser. Se olvida así que la sociedad y la cultura constituyen la matriz de todo lo que se da. Matriz tanto en su sentido femenino de lugar en donde se gesta y sostiene la vida (el vientre y la tierra), como en el sentido masculino de patrón según el cual o de acuerdo con el cual se concibe (el modelo o proyecto a seguir). Hay que recordar que el pensar no se hace en total libertad, es respuesta, réplica e inquietud. La abstracción que viste de desinterés al pensador y lo convierte en profundo o el método que inviste al pensamiento de objetividad y seriedad pueden convertirse en otra invitación más al conformismo y a la adaptación. Por el contrario cada pensador nos debe su invitación al viaje, a salir a campo abierto. Pensar es alejarnos del refugio para subir a lo alto de la región y observar desde allí nuestra villa como un conjunto, entre otros, de 
luces que iluminan la noche. Desde lo alto de la montaña vemos que nuestro refugio es uno más entre tantos y recién allí, con ojos de extranjeros iniciamos el verdadero viaje del que nunca habrá regreso. El éxodo de las certidumbres cotidianas, de las creencias de nuestros contemporáneos, de las esperanzas de los antepasados y de las proyecciones que aprendimos a desear distingue al pensador apasionado del conformista. Iniciar el camino, distanciarse, hacerse extranjero. Mirar de nuevo, sentir la inquietud e interrogar. Sólo entonces pensar se convierte en la posibilidad de poner en escena las mismas historias que vemos, con los mismos actores pero con la perspectiva de la altura que está lejos de ser la elevación divina de la objetividad. Es la perspectiva del caminante, del extranjero, del que está en tránsito. Así el pensamiento aparece como una escenificación de la inquietud para que los actores se vean reflejados en el espectáculo de sus acciones y de sus palabras. Entonces el pensador podrá ser calificado de crítico mordaz y demoledor y en esa acusación se verá a sí mismo como extranjero en el territorio de las explicaciones seguras.

Interpretar lo que sucede es una puesta en escena de lo visto para que las seguridades que tranquilizan las conciencias se reflejen en el espectáculo de su propia actuación. Así convertidas en espectadoras de su propia realidad pueden romperse como clausura. El quiebre, la fractura, la hendidura convertidas en pequeños pasajes de luz permiten ver la "realidad" de otra manera. Con esas visiones comienza una posibilidad: liberar la imaginación y soñar con otras explicaciones. En este momento el pensamiento se convierte en respuesta creativa, en creación de un mundo de significaciones. Yen una sociedad llena de distracciones y entretenimientos el espectáculo de sus propias creencias se transforma en una provocación obscena (en el sentido de Baudrillard como "fuera de escena").

\section{La luz mala}

Un hombre del pueblo de Neguá, en la costa de Colombia, pudo subir al cielo. A la vuelta, contó. Dijo que había contemplado, desde allá arriba, la vida humana. Y dijo que somos un mar de fueguitos. El mundo es eso - reveló - un montón de gente, un mar de fueguitos. Cada persona brilla con la luz propia entre todas las demás. No hay dos fuegos iguales. Hay gente de fuegos grandes y fuegos chicos y fuegos de todos los colores. Hay gente de fuego sereno, que ni se entera del viento, y gente de fuego loco, que llena el aire de chispas; algunos fuegos, fuegos 
bobos, no alumbran ni queman, pero otros arden la vida con tantas ganas que no se puede mirarlos sin parpadear, y quien se acerca se enciende. (E. Galeano)

Se le llama "fuego fatuo" a la inflamación de ciertas materias que se elevan de las sustancias animales o vegetales en putrefacción, y forman pequeñas llamas que se ven andar por el aire a poca distancia de la tierra. En el campo argentino y uruguayo recibe el nombre de "luz mala" o de "Farol del Mandinga" y es una creencia muy popular. La luz, que aparece al anochecer sobre todo en temporada seca, es temida por que se ve en ella el alma de algún difunto que no ha purgado sus penas y que, por ello, sigue de esa forma en la tierra. Generalmente, por miedo, nadie cava donde sale la luz. Los pocos que se han aventurado a ver que hay abajo de la luz siempre han encontrado objetos metálicos o alfarería indígena. Muchas veces se han hallado urnas funerarias con restos humanos, lo que aumenta el terror ya que al ser destapada despide un gas a veces mortal para el hombre. Por ello los lugareños aconsejan tomar mucho aire antes de abrir o, de lo contrario, hacerlo tapado con un poncho, de suerte que el tufo no llegue a ser respirado. Otros aseguran que para liberarse de la luz mala se debe rezar y luego morder la vaina de un cuchillo, ya que el arma blanca es la única defensa posible.

En la creencia criolla del Farol de Mandinga el fuego fatuo es considerado una manifestación de ultratumba. La fuente de iluminación proviene del abajo, del inframundo precristiano que, para los aborígenes, era el lugar de los muertos pero no por ello un lugar "malo". De allí que lo llamaban "ailen mulelo" que significa "brasa ardiente que anda o camina" ("ailliñ": brasa, y "amulen": andar, deambular, caminar). Tal vez sea ese el significado de la visión del hombre que pudo subir al cielo y revelar que la humanidad es un mar de fueguitos en la que cada persona brilla con luz propia.

Si algo de esto fuera así, el pensar filosófico no sólo puede ser abordado desde las metáforas de la luz de la razón o de la iluminación divina. En definitiva de la metáfora de una iluminación activa. La luz mala es el resto de brillo, lo que queda de lumínico del ser humano. Durante el día la ceguera producida por el exceso de luz no deja ver lo que es, en la oscuridad de la noche vemos una luz tenue que se mueve, es el resplandor de lo que permanece del mundo diurno de lo humano. Sobre el fondo de oscuridad destacamos la luz; la noche, la penumbra y las sombras son una condición necesaria de la visión 
y por ello, del pensar. Como afirma G. Durand, la noche tiene una existencia simbólica autónoma, sin embargo, no hay luz sin tinieblas. Simbólicamente la oscuridad se da por existente, lo que necesita explicación es la luz. Entre otras cosas porque el exceso de luz tiene el mismo efecto que se atribuye a la oscuridad: enceguecer.

Una cultura que sataniza la oscuridad y propone el "echar luz" sobre los problemas como modelo del pensar, obliga a rescatar lo oscuro subterráneo en su realidad arquetípica como destino y fuente de lo humano. En la oscuridad se agudizan los otros sentidos, se inhibe la mirada y se estimula la percepción auditiva, táctil, olfativa e incluso, gustativa. La luz mala acarrea una verdad oscura que, sin embargo, se escucha, se toca, se huele y se gusta. El inframundo constituye una condición indispensable para la filosofía y es una de las razones por las que fácilmente se la tilda de oscurantista y poco "práctica". Sin embargo, la actitud positivista e ilustrada que echa luz sobre las cosas y así las resuelve es, en este sentido, insensatamente testaruda. Está embriagada de seguridad y optimismo, lo que hace recordar al ebrio de la historia anónima popular que "en plena noche buscaba algo debajo de una farola, cuando pasa otro y le pregunta: ¿qué haces ahí? -Busco mi llave, le responde tambaleante y con la voz quebrada. -¿Estás seguro de que ha caído debajo de la farola?, le insiste su amigo.

-iNo, estoy seguro de que ha caído en otra parte! -Sorprendido le pregunta: Pero, entonces ¿por qué la buscas debajo de la farola? -iPorque aquí hay luz! Le respondió".

La filosofía se atreve a la oscuridad y desde allí le plantea al saber la necesidad, por un lado, de dar una mejor respuesta a la complejidad y, por el otro, de considerar el terreno sobre el que se erige. La filosofía invita a adentrarse a terrenos "prohibidos" por metodologías, autores y costumbres académicas; llama a leer mapas olvidados y recorrer caminos y senderos dejados de lados. Filosofar es errar en el sentido de andar vagando y, por ello, también en el sentido de no acertar.

Lejos de ser una propuesta de contemplación pasiva, el pensar filosófico invita a moverse. Conduce al pensador hacia el campo abierto de los saberes, a la intemperie de las seguridades y al lado oscuro de las certezas. 
La luz mala no es "mala iluminación", en el sentido de la afectación de la capacidad de distinguir con precisión los detalles de los objetos del campo visual. La luz mala, reverberación de lo putrefacto para la ciencia es, para el pensar filosófico, la manifestación del inframundo del sentido.

La iluminación eléctrica en su intento de alumbrarlo todo es la contra cara tecnológica de la satanización simbólica de la oscuridad. La civilización de la luz que de ella resulta lo irradia casi todo multiplicando, casi al infinito, las más diversas fuentes lumínicas. La cantidad de estímulos visuales de luces y movimientos ha engendrado una sociedad que padece de nistagmus, es decir, de un movimiento incontrolado e involuntario de los ojos. Hay tanto para ver que es imposible percibirlo todo ni siquiera, con esa actitud tan típica y característica del hombre actual que es el zapping.

La civilización de la luz sólo es compatible con una sociedad que no puede fijar la mirada. El problema de visión del hombre actual no es la ceguera sino el nistagmus. Por ello, la filosofía esta obligada, más que nunca, a señalar aquél brillo movedizo y solitario que, en medio de una noche sin luz artificial, recuerda la penumbra original de la que el enceguecido humano partió.

\section{La oscuridad y la luz}

La oscuridad se da por existente. Lo que hay que explicar es la luz. Tal vez por ello según el libro del Génesis lo primero que dijo Dios fue "haya luz" y acto seguido "vio que era buena y la separó de la oscuridad". Abriéndose paso en medio de la oscura noche nació el día. La luz inaugura los días como ciclo permanente de luz y oscuridad. La luz fue la primera palabra de Dios y el primer acto en el que vio la bondad de su obra. El origen de la oscuridad no aparece como problema, lo que se quiere explicar es el sino el principio de la luz, la claridad, la iluminación y lo iluminado. Tal vez por ello se pueda reconocer en la acción que describe el texto bíblico el constante esfuerzo de la humanidad por iluminar. Iluminar como sinónimo de bien -la luz de la gracia-de educación - la luz de la razón-, en definitiva, la luz como espacio donde se desarrolla la vida frente a la oscuridad como lugar de lo que no puede verse, no puede ser mirado. La noche y la oscuridad tendrá por ello un poder ambiguo: es lo que no deja ver y al abrigo de la cual se produce todo tipo de fechorías pero, es también, el espacio y el momento en el que se 
revelan verdades (el "búho de Minerva") o se produce la salvación (Moisés y su pueblo escapan en la noche). En cierto sentido, el día facilita la visión de la realidad en su extensión, la noche la concentración en su intensión. El lugar que ocupa el ciego en muchas culturas antiguas parece reforzar la idea de que la visión del alma -la comprensión, la sabiduría-se da en la oscuridad.

El día y la claridad tienen lugar en la superficie poblada de objetos y gentes. La noche tiene afinidad con las profundidades como la de la cueva, la gruta, la caverna, el cráter. Posiblemente porque en la naturaleza la fuente de luz proviene de arriba. La luz que disipa la noche proviene de lo alto, el abajo es lo que debe ser iluminado.

"Luz y superficie" versus "oscuridad y profundidad". Relación de oposición y de mutua implicación que se presenta como una de las distinciones con la que se explica, de diversas maneras, la presencia del sentido, el significado y la significación. La comprensión y la explicación deben iluminar lo oculto del sentido y el significado. Hermenéuticas y herméticas crítica y críptica tienen en común esta relación entre la superficie extensiva de la existencia (de la vida, del texto, etc.) y la profundidades intensivas de su soportes y fundamentos.

\section{El infierno del sentido}

Los limites del alma no lograrías encontrarlos, aun recorriendo en tu marcha todos los caminos: tan profunda es su razón. (Heráclito)

Lo subterráneo es el infierno -infernun: lugar de abajo. Me refiero a una concepción del infierno anterior a la cristiana medieval donde se convirtió en un instrumento pastoral y de educación en el miedo.

Muchos son los nombres con que se da cuenta de la realidad del inframundo en la literatura antigua, entre ellos, Hades para los griegos; Sheol para los judíos; Gehena para los evangelistas; Mictlán para los aztecas; Hel para los antiguos pueblos germánicos; karta, vavra o parshana para los antiguos egipcios; y muchos más. Aunque la lista es muy incompleta interesa rescatar que en casi todas las culturas antiguas el infierno se asocia a un lugar "abajo" y a la oscuridad. Posiblemente el desconocimiento sobre el destino en ese "más allá" se asociaba a esa oscuridad unida a la acción de enterrar, de poner bajo tierra, a los cadáveres. Aunque las diversas prácticas mortuorias no permite afirmarlo de todos los pueblos importa llamar la atención que el infierno antes de ser 
el lugar de los condenados es la morada de los muertos. Allí están, allí viven y desde allí pueden volver.

Hacia el año 500 a.C. en la mitología del Hades griego aparece un nuevo personaje: el barquero Caronte (Díez de Velasco 2004). Caronte aparece como la antítesis del genio heroico que cobra una mínima cantidad por el pasaje: "es la forma de democratizar el viaje al más allá: es el psicopompo popular, representación de una muerte aceptable para los grupos populares de Atenas, que ... son el sostén de la democracia” (ibídem).

La entrada al infierno se ubica en cuevas o cráteres y el medio para llegar es generalmente acuático. Virgilio en Eneida lo ubica su entrada en el pantano de Aqueronte, cerca de Cannes. Yun autor contemporáneo comenta "la actividad volcánica de esta región y sus paisajes lúgubres establecerán sólidamente su reputación: durante mucho tiempo, las bocas del infierno se ubicarán entre el Vesubio y el Etna, en Campania o en Sicilia” (Minois 2004, p. 51).

Una vez adentro el medio más característico en el imaginario griego de la muerte es el agua (Díez de Velasco 2004, p. 5).

Los grupos gnósticos mistéricos redefinieron el papel del agua en este tránsito al más allá. Estar iniciado a lo misterios será una condición necesaria para no perderse en el inframundo. En su viaje el viajero experimenta una gran sed que, sin el conocimiento necesario, bebe de la fuente equivocada que le anula la memoria y le embrutece el alma. La sabiduría necesaria tiene como ingrediente fundamental la memoria sin la cual se bebe del agua equivocada, el agua del olvido. Bebiéndola el alma se embrutece y se lanza a una nueva vida en la tierra sometida a la ignorancia y la desdicha. Y con ello se inicia la repetición. Si en cambio el viajero iniciado en los misterios bebe el agua de la memoria se abre paso a una bienaventuranza post-mortem reservada a los que saben.

Los griegos antiguos, quizá acostumbrados a que el agua otorgase tanto riqueza como naufragio y aniquilación, tanto prosperidad como agostamiento a los campos, parece que defendieron el valor ambivalente de ese elemento al imaginarlo en los límites del morir. El agua es camino al más allá, marca la senda del no retorno y a la par caracteriza el viaje. Pero no es pura aniquilación porque no todas las aguas inframundanas son semejantes, habiéndolas... dadoras o conservadoras de la memoria en las especulaciones de filó- 
sofos y místicos. El viaje acuático se resuelve con un éxito necesario para el iniciado, Caronte solo se llevará a los ignorantes. ${ }^{1}$

En el viaje de la muerte y por medio del control de la memoria se les muestra al viajero iniciado la verdadera vida, "el viaje al más allá se transforma en la mejor de las oportunidades de comprender que el engaño del aciago destino humano consistía en que el punto de partida y de llegada estaban trastocados y de este modo poder retornar al que imaginaban verdadero hogar" (ibídem, p. 12).

Este intermedio tiene como objeto destacar la metafórica arquetípica de la relación entre la superficie y el inframundo, por un lado, y la génesis e interpretación del sentido por el otro. Si en la obra de Maffesoli destaca la hipótesis de la centralidad subterránea como un elemento específico de su sociología es posible radicalizar aún más esta suposición para pensar la cuestión del sentido, lo imaginario y su interpretación.

De acuerdo con la breve descripción detallada podemos considerar al sentido dado como renacimiento desde lo imaginario posibilitado por el olvido. El olvido abre las puertas de la existencia a lo que está y/o debería estar en la oscuridad del inframundo, lo no visible o invisible aparece. Dicho de otra manera, la contingencia de la existencia de las palabras y los textos resultan de un olvido. La condición de posibilidad de existencia del sentido y el significado es el olvido de su procedencia y de su origen imaginario. Y, por lo tanto, su interpretación implica memoria y recuerdo, sumergir las materialidades existentes al infierno desde el que un día se reencarnó. Como afirma Hillman "la interpretación, como el soñar, es un morirse para el mundo diurno al transformarlo de una realidad literal a una realidad metafórica" (Hillam 1994, p. 185).

\section{El descenso al infierno}

Lo subterráneo implica reconocer que la realidad no es necesaria sino contingente y por lo tanto, plural, polisémica y ambivalente. Lo definido y delimitado como cosa es una reunión de elementos heterogéneos llamados a existir como tal cosa por la acción humana.

\footnotetext{
${ }^{1}$ Ibídem, p. 11; cfr. Minois 2004, pp. 51-53.
} 
La cosa social es obra humana, es reunión creativa, es institución desde el fondo subterráneo donde todo permanece mezclado y confundido. La realidad es "conjunto heterogéneo" en tanto entramado de diversos constituyentes, de diferentes niveles y procedencias, permanentemente unidos de un modo particular desde lo imaginario instituyente. Lo magmático como modo de ser fundamenta la heterogeneidad en la psique y en la sociedad, es decir, en el dominio mismo del pensamiento.

Lo heterogéneo, al igual que la imaginación, corrompe nuestro modo habitual de analizar y pensar lo dado, porque su naturaleza magmática tienta, hace superponer planos que generalmente intentamos mantener separados, ligando lo racional con lo irracional (Franco 2003, p. 68).

Las obras del hombre -la política, la cultura, la técnica-son significaciones instituidas o imaginarios segundos que remiten al magma de lo imaginario social, imaginario primero o radical. Como toda definición que se quiera hacer desde lo imaginario, envía lo supuestamente conocido hacia el plexo de significaciones sociales. Un envío que hunde "la realidad" en el magma de lo imaginario para hacer resurgir desde allí una nueva caracterización bajo el signo de la arbitrariedad.

La arbitrariedad no es convención, si no reunión de lo que es aparentemente heterogéneo a priori. Porque si las significaciones imaginarias sociales son emergencia - por condensación, solidificación y sedimentación-del magma de lo imaginario en un momento dado, su interpretación debe proceder sumergiendo nuevamente las significaciones vigentes en lo imaginario para hacer re-surgir nuevos sentidos. Se trata de hacer una inversión, un retorno, un "regreso del fenómeno a su contexto imaginario" (Hillam 1994, p. 136). Como afirma Henry Corbin comentando el Islam y el método ta'wil "se deben hacer volver con el pensamiento configuraciones perceptibles a configuraciones imaginarias y luego elevarse a significados aún más elevados". ${ }^{2}$

La interpretación de y desde lo imaginario implica una concepción antropológica del sentido y de la significación como surgimiento y flujo incesante. De manera que sentido y significación constituyen sim-bolos, es decir, unión y sutura de lo distinto, separado y distante de lo originario. En esta metafórica la interpretación implica, entonces,

\footnotetext{
${ }^{2}$ Citado en ibídem.
} 
caracterizar las significaciones de la sociedad como un todo indistinto, en el que se confunden (confundere) o mezclan elementos diversos; tomar las significaciones solidificadas para sumergirlas en el magma imaginario, es decir, fundirlas (fundere), derretirlas y licuarlas; buscar nuevas articulaciones de sentido, esto es, refundar (ya que en su "origen" las significaciones fueron fundadas -fundare-) nuevos sentidos; reintroducir las nuevas significaciones en la sociedad, o sea, difundir (diffundere), no sólo en el sentido de esparcir o propagar sino, sobre todo, como reintroducir cuerpos "extraños" en la homogeneidad social. Esta última acción es la dimensión pedagógica y política de la interpretación.

Si las significaciones son surgimiento de sentido e institución de la sociedad (de la confusión-caos a la fundación; del infierno a la tierra de los vivientes, de la inconciencia a la conciencia), la interpretación es resurgimiento que tiende a la refundación social. La interpretación es entendida así a la manera de un proceso alquímico: reducir cualquier sustancia a una masa informe e indistinta (nigredo); recuperar en ella los cuatro elementos y refinarlos (ablutio); reestructuraros de forma equilibrada (congelatio); fijar (fixatio) la perfección así obtenida. El producto de este proceso se utilizaba como fermento para la perfección de otros cuerpos. La interpretación supone el juego entre heterogeneidad y homogeneidad como nota constitutiva y constituyente de la existencia de las obras de la cultura en tanto significaciones imaginarias sociales. Lo que implica que, desde las distinciones y definiciones dadas explícitamente por los discursos sociales, se procede a volver o, mejor aún, devolver las significaciones establecidas a lo magmático. Para ello se establecen nuevas relaciones basadas sobre las discontinuidades 1 y las semejanzas y similitudes escondidas que representan, a la vez, lo impensable y lo que esta dado.

Así, la discontinuidad aparece como resultado de la consideración de la significación como acontecimiento disperso, fruto de decisiones, elaboraciones, iniciativas, accidentes, pero a la que se le han reducido, borrado, destacado sus límites para que aparezca inserta coherentemente en la continuidad de las significaciones y en la homogeneidad de las instituciones. Continuidad, coherencia y homogeneidad constituyen las notas características de la clausura simbólica de las significaciones instituidas. De ellas parte la interpretación para reintroducirlas en la incoherencia, la discontinuidad y la heterogeneidad del flujo incesante de lo imaginario social, en el infierno del sentido. 
En la interpretación se procede, entonces, de la distinción instituida a la indistinción-fusión y a una nueva distinción, al modo de nueva articulación de sentido. Las discontinuidades de los acontecimientos, la incoherencia simbólica y la heterogeneidad radical son tanto claves del surgimiento del sentido como de su comprensión. Frente a la institución de la sociedad que procede de lo instituyente a lo instituido, la interpretación se orienta en la dirección contraria: de lo instituido a lo instituyente y vuelta a lo instituido con nuevas conexiones de sentido. La institución es instauración de una constelación de significaciones con coherencia y cierre por lo cual, toda interpretación es una reinterpretación, aunque para simplificar se siga utilizando el término "interpretación".

En el camino de la interpretación se postulan los procesos que semiótica y psicoanálisis reivindican para la lectura de las significaciones: condensación, desplazamiento, deformaciones, negaciones, olvidos, repeticiones, separaciones, simbolizaciones, etc. El análisis social busca a través de estos procesos "atender el destino de la espontaneidad humana" (Joas 1998, p. 102). Destinos que según el psicoanálisis son: la sublimación, la represión, la trasformación en lo contrario o la vuelta sobre la propia sociedad. El imaginario interpretado se presenta como surgimiento no sólo heterogéneo, sino también conflictivo entre diferentes visiones, imágenes y significaciones. El imaginario interpretado descubre el imaginario materializado como un espacio agonístico en dos sentidos. En un sentido radical, combate del hombre con el "destino", el "sin sentido" y lo ilimitado e infinito. El imaginario aparece como testimonio de una historia que arrastra al hombre en su trágico camino por el universo. En un sentido derivado o segundo, no secundario, la lucha es pugna de los diferentes individuos, grupos, estratos, clases, sociedades y pueblos por el dominio y el poder. Donde el poder, entendido en un sentido amplio, se entiende como "la estructura más desconcertante de la existencia" (Ricoeur 1994, p. 325), alrededor de la cual se organiza gran parte de la vida de la sociedad. Lo imaginario implica heterogeneidad radical -discontinuidad de los acontecimientos e incoherencia de las significaciones-y lucha y conflicto - fruto de lo imponderable del destino, el sin sentido y del combate por el dominio-. Por ello, es necesario, en primer lugar, proponer las realidades sociales como significa- 
ción imaginaria materializada - confundida - a fin de, en segundo lugar, volver -fundir- sobre lo imaginario social.

\section{La profundidad y lo invisible}

La naturaleza ama el ocultarse. (Heráclito)

Lo social tiene como nota característica la profundidad de su razón, de su logos. Una profundidad inagotable y fuente de lo que se da como sentido. El sustrato de la sociedad es el infierno del sentido que, como el Hades griego, significa invisible y oculto. Pero lo subterráneo del sentido comienza en el basurero, el lugar donde ser arroja lo rechazado, lo negado y también lo olvidado como sin sentido. Allí la inmundicia está formado por los cadáveres de lo rechazado, lo abandonado, la basura maloliente: imágenes, metáforas, frases, palabras que pasan de moda, que dejan de usarse, que pierden importancia o que ya no significan, ni denotan, ni connotan, ni muestran casi nada.

Lo subterráneo es también, la fuente de la que todo aquello regresa y se reencarna constantemente con nuevas formas. El inframundo habitado por los demonios y los espíritus de los muertos: son los arquetipos, los símbolos, los mitos y los dioses que reencarnándose de mil maneras dan contenidos y rostro a las inquietudes humanas expresadas históricamente. En tercer lugar, lo subterráneo del sentido constituye sobre todo, el humus y la matriz de todo lo que se da como sentido y de las categorías que lo instituyen. Se trata del vacío y la profundidad abisal: la profundidad desde la que se define toda profundidad. No es un vacío pero si una invisibilidad, una oscuridad o tal vez un exceso de brillo. En todo caso aunque se mire no se ve. La profundidad radical es categorías y matrices elementales con las que se piensa lo subterráneo. Un cierto silencio la envuelve, un no poderla nombrar que convierte en abuso del lenguaje hablar de "profundidad". Está, se sabe, porque actúa. Es la fuente de la novedad, la condición de posibilidad y de representabilidad de lo que se da como realidad social. Inmundicia, demonios y vacío son aspectos del infierno de lo social. Lo oculto de lo social. Lo subterráneo, en tanto oculto, resulta inquietante y amenazante para cualquier proyecto de control de la naturaleza, del hombre, de la sociedad y, de racionalidad.

La armonía con lo oculto, con lo oscuro y con la profundidad incomoda el espíritu de la ilustración y a sus hijas las ciencias sociales. La hermenéutica y 
la hermética deben descender a los infiernos, a la cripta y a lo críptico de lo social. El acción de iluminar no implica la de negar como parece suponerse en la tradición cristiana occidental donde el dogma del descenso al infierno de Cristo es para que ya ningún creyente tenga que pasar por allí. En la teología paulina la inmersión del bautismo significa un entierro y resurrección del hombre para la vida nueva. A partir de ese momento al cristiano no le hace falta entrar en el infierno, Cristo ya lo cerró para él. El cristiano profesando la fe y con el bautismo ha tomado un atajo hacia el cielo que no pasa por el territorio de los muertos. El infierno convertido en el lugar de los condenados no es un lugar para desear estar.

Entre los griegos el héroe entraba al Hades y gracias a sus grandes obras permanencia en la memoria del pueblo. Otra cosa es la tradición que ubica un ayudante del viaje al territorio de los muertos. Caronte, cuyo nombre significa "brillo intenso", es un barquero que por un óvolo conduce hacia el puerto adecuado. Yasí invita a reconocer que el viaje al infierno es posible y necesario para todos.

Cada acto humano implica un descenso al infierno, cada acto de interpretación significa hacer comparecer lo existente con lo que allí no se ve, recordando olvidos. La acción y el pensar -mejor, la interpretación crítica y creativa- son caminos por donde viaja la creación y recreación de la sociedad. Como consecuencia la acción, el pensar y la humanidad puede darse como concluso y concluido.

\section{Hacia los cenotes de lo social}

Los colores y los significados de las palabras no existen. Así como seguimos diciendo que el sol sale por el este, se suele sostener que el color es una característica fundamental de los objetos: un lago azul, una casa rosada, etc. Sin embargo, esta noción popular de los colores no es real. El color con que vemos las cosas depende de procesos biológicos que se producen en los ojos y en el cerebro. El cerebro procesa la forma de un objeto y su color siguiendo dos vías separadas y que, aunque la forma y el color de los objetos normalmente estén relacionados, la representación neuronal del color puede "sobrevivir" sola, sin forma que la acompañe. Cuando esto sucede, el cerebro establece una nueva relación entre "ese color" y una forma visible alternativa. Es decir que los 
colores son construidos de la misma forma que se construyen los significados de las palabras. ${ }^{3}$ La construcción cerebral de los colores solo es un ejemplo que podemos utilizar para volver a pensar en las creencias y convicciones que sirven para justificar un estado de cosas, una sociedad e incluso una filosofía. El que piensa pierde. Pierde seguridad, quietud, y referencias existenciales. La presente invitación a lo subterráneo y a la oscuridad es una sugerencia para activar otras metáforas, imágenes, sonidos, mitos, etc. que desde lo que no vemos pero que percibimos por sus olores - como las inmundicias-, sus sonidos -como los "ruidos" de la teoría matemática de la información- y sobre todo, por el miedo a entrar al cenote que con su frescura y su oscuridad nos invita ver de otra manera los mismos rayos del sol que desde afuera nos ciegan y desde adentro se descomponen en colores y sombras.

\section{Referencias}

Bajtin, M.M., 1993, Problemas de la poética de Dostoievski, Fondo de Cultura Económica, Buenos Aires.

Díez de Velasco, F., 2004, "Imaginando el más allá en el mundo griego", en Sánchez León 2004. Consultado en versión electrónica en http://webpages.ull.es/users/fradive/artic/masallapalma.pdf, p. 5

Foucault, M., 1995, La arqueología del saber, Siglo XXI, México.

Franco, Y., 2003, Magma. Cornelius Castoriadis: psicoanálisis, filosofía, política, Biblos, Buenos Aires.

Hillam, J., 1994, "El sueño y el inframundo", en Kerényi, Neumann, Scholem y Hillman 1994, pp. 135-219.

Joas, Hans, 1998, El pragmatismo y la teoría de la sociedad, CIS/Siglo XXI, España.

Kerényi, K., E. Neumann, G. Scholem, J. Hillman, 1994, Arquetipos y símbolos colectivos. Círculo Eranos I, Antrhopos, Barcelona.

Kristeva, J., 1978, Semiótica I y II, Fundamentos, Madrid.

Minois, G., 2004, Historia del infierno. De la Antigüedad hasta nuestro días, Taurus, México. Ricoeur, P., 1994, Ideología y Utopia, Gedisa, Barcelona.

Sánchez León, M.L., 2004, El más allá, Universidad de La Laguna, Palma de Mallorca. Shevell, S., 2009, "Study Shows That Color Plays Musical Chairs in the Brain", en http://news.uchicago.edu/news.php?asset_id=1721.

${ }^{3}$ Cfr. Shevell 2009. 